\title{
A Method on Assessing Complication-Base Risk Factors for Neonatal Morbidity: Application for Pattani Hospital Delivery
}

\author{
Orasa Rachatapantanakorn \\ Universal Coverage and Social Welfare, Pattani Hospital \\ Pattani 94000, Thailand \\ Tel: 66-73-337-619Ｅ-mail: satanakorn@yahoo.com
}

Phattrawan Tongkumchum (Corresponding author)

Department of Mathematics and Computer Science

Faculty of Science and Technology, Prince of Songkla University

Pattani 94000, Thailand

Tel: 66-73-312-179Ｅ-mail: tphattra@bunga.pn.psu.ac.th

\author{
Nittaya McNeil \\ Department of Mathematics and Computer Science \\ Faculty of Science and Technology, Prince of Songkla University \\ Pattani 94000, Thailand
}

Tel: 66-73-312-179Ｅ-mail: nittaya@bunga.pn.psu.ac.th

\begin{abstract}
We investigated risk factors for neonatal morbidity based on a database of 19,268 singleton maternal deliveries at Pattani Hospital during the period from 1 October 1996 to 30 September 2005 inclusive. This database includes demographics of the mother and delivery outcomes including birth weight, one- and five-minute Apgar scores, and at most one complication selected from a list of 62 by the deliverer. In our study the neonatal risk associated with a complication was defined by averaging the results given by 11 obstetricians who independently scored each complication on a scale from 0 to 9 (highest risk to baby). Using logistic regression to adjust for demographic and pregnancy-history factors, we found risk that Muslim women have higher neonatal morbidity risks, particularly those associated with severe pregnancy-induced hypertension, eclampsia and thick mecomium stain.
\end{abstract}

Keywords: Neonatal morbidity, Demographic factors, Ethnicity, Logistic regression analysis

\section{Introduction}

The World Health Organization estimated that more than nine million infants die each year before birth or in the first few weeks of life, with nearly all of these deaths occurring in developing countries. Most of these deaths were caused by pregnancy related complications such as placenta previa and abruption placenta, and delivery related complications including intrapartum mortality (WHO, 1999). In their review of maternal health in poor countries, Filippi et al. (2006) pointed out that $2.4 \%$ of neonates are stillborn and another 3\% die within 30 days with many due to obstetric complications, and that mother and child outcomes are closely linked. A systematic international review of causes of maternal death by Khan et al. (2006) found abortion and complications leading to hemorrhage, hypertensive disorders and sepsis as leading factors, depending on the region.

In developed countries the maternal mortality risks are now quite low, although a study by Berg et al. (2005) found that $40 \%$ of deaths due to pregnancy complications were potentially preventable. Wen et al. (2005) suggested that in 
industrialized countries such as Canada maternal morbidity based on delivery complications including venous thromboembolism and uterine rupture should be used instead of mortality as a health care measure.

If a pregnancy complication is assessed as high, preventative medical practices to assist the newborn's survival could be undertaken. Early detection of risk factors in pregnant women is important. Identifying neonatal morbidity risk can help health officers to ensure that pregnant women receive proper care, thereby significantly decreasing maternal and neonatal morbidity and mortality rates (Dangal, 2007). However, assessing the pregnancy complication risk based on the mother's demographic and pregnancy history has not been seriously addressed, especially in developing countries.

In Thailand the major important causes of maternal death in 2003 were hemorrhage (27.8\%), indirect cause (21.4\%), hypertension (16.7\%), amniotic fluid embolism (11.9\%), sepsis (8.7\%), and direct cause (8.7\%) (Ministry of Public Health, 2004).

Located in southern Thailand with population 85\% Muslim, Pattani province had perinatal mortality rates 11.4 and 13.0 per 1,000 total births in 2004 and 2005 respectively (Pattani Public Health Provincial Office, 2005). Although perinatal morbidity in the three Muslim majority southern provinces of Thailand is relatively high compared to the predominantly Buddhist provinces to the north, it is difficult to get precise estimates of the underlying relative risks for two reasons. First, birth certificates do not routinely record data other than the birth weight and length, 1-minute and 5-minute Apgar scores, the mother's age and the location of the hospital (rather than the mother), and hospital records of perinatal morbidity including complications are not routinely reported to Public Health authorities. Second, the morbidity rates, even for the less serious complications, are too low to accurately compute relative risks unless the sample size is very large.

However, if a complete record of delivery complications and full demographic information about the mother is recorded consistently by birth attendants at a major hospital over a period of several years, these data can be used to estimate the risk of a serious complication, and to compare these risks with respect to demographic and pregnancy history factors. Provided the risk associated with each complication is known, this can be done even if the actual morbidity events themselves are not recorded at the time, as is often the case when such problems manifest themselves much later. To do this, it is necessary to have estimates of the risk of perinatal morbidity associated with each recorded complication. These estimates can then be applied to estimate the risk itself based on the complication that occurred.

\section{Materials and methods}

\subsection{Selection of data}

We selected Pattani Hospital for our study because it has an ongoing well-maintained computerized database with case-by-case records containing birth outcomes including complications as well as 1- and 5-minute Apgar scores and birth weights, and demographic and pregnancy history data for the mother, for all deliveries since 1 October 1996. Our study included deliveries before 30 September 2005. This sample does not reflect births in Pattani Province as a whole, because there are other hospitals, and not all births occur in hospitals. Of the 12,587 births recorded in Pattani province in 2003 and 2004 respectively, 14.4\% and 19.0\% of mothers delivered in Pattani Hospital, $61.7 \%$ and $64.0 \%$ in community hospitals and $23.9 \%$ and $17.0 \%$ with traditional birth attendants (Pattani Public Health Office, 2005).

We excluded women having multiple births (329 deliveries) or previous caesarean births (3,311 deliveries) because no complication was recorded for such deliveries even if one existed. Transferals from another ward and referrals from another hospital (3,250 deliveries) were also excluded because they tend to have much higher morbidity than new cases. The data were entered into a database by nurses at Pattani Hospital, based on information in the hospital records system, giving a study sample of 19,268 for the nine-year period.

\subsection{Determinant and outcome variables}

The main outcome variable was the risk to the baby, based on the expert opinions of a panel of 11 obstetricians who gave a score from 0 to 9 for each of 62 complications specifying the condition of the infant after birth. These 62 complications were gathered from the existing maternal delivery records in computerized database for 10 years (1996 2005). Therefore, all possible mothers' complications were included in this study. A serious complication was defined as one given a score of 7 or more. Other outcomes of interest were one-minute and 5-minute Apgar scores and birth weight. Seven categorical determinants associated with the mother were considered, classified as follows: religion (Islamic or other), education (primary school, junior high school, senior high school, diploma/bachelor's degree, or other), occupation (housewife, government officer, farmer/gardener, business, worker, or other), number of previous pregnancies (gravidity: 0, 1, or more than 1), mother's age (less than 20, 20-24, 25-29, 30-34, or 35 or more), budget year of delivery (defined as the period from 1 October in the preceding calendar year to 30 September in the current year) from 1997 to 2005 inclusive, and residence (15 regions comprising seven based on sub-districts of Pattani city, six based on other districts of Pattani province, Songkla province, or other). In each of these categories 'other' includes 'not stated'. 


\subsection{Severity score for complications}

For reasons stated earlier the study did not use an observed outcome because mortality was rare. While manual guidelines are used for detecting possible complications based on the mother's obstetric history there is no objective measure of morbidity based on all the delivery complications that routinely occur. We used a score for predicting the morbidity risk based on the assessments of eleven obstetricians personally known to the first author and working in three hospitals: Pattani Hospital (4), Chiang Mai Hospital (4) and Trang Hospital (3). All eleven agreed to provide their assessments when approached.

The obstetricians were asked to assess on a scale from 0 (no risk) to 9 (most serious risk), the risk to the baby for each of the 62 delivery complications listed in Table 1. These 62 complications were the ones routinely recorded at the hospital, largely by the same delivering personnel over the period of data collection. Although some of them are associated with very low risk and arguably could be omitted from consideration, and others were not defined as accurately as they could be, and the list could be expanded to more accurately reflect changes in medical practice, all were included without any further redefinition, in the same order as on the hospital's list, to ensure that the opinions of the obstetricians were not preempted or biased by any factors other than their own personal judgments.

The average for the 11 assessors - also given in Table 1 - was then taken as the risk score for each complication. For each complication, the average range (disagreement) in scores between the 11 assessors was 4.2. The complications whose associated risks they agreed on most were DFIU (complete agreement), anancephalus, eclampsia, prolapsed cord, and uterine rupture (range 1), and fetal distress, oligahydramios, and thalasemia in pregnancy (range 2). The complications whose associated risks differed most between assessors were transverse lie (range 8), low fetal movement and placenta previa (range 7) and anemia, asthma, appendicitis, condyloma, gut obstruction, epilepsy, fever, myoma uteri, prolong stage 2, trauma, and VDRL positive (range 6).

\subsection{Statistical methods}

Preliminary statistical analysis involved examining the frequency distributions of the determinants and their univariate associations with the outcome.

We used logistic regression (Kleinbaum and Klein, 2002) to estimate odds ratios and their 95\% confidence intervals to compare the high-risk outcome with respect to each determinant both before and after adjusting for the six other factors. For each risk factor the referent category for the odds ratio was taken to be the one with the largest frequency, thus minimizing the widths of confidence intervals for individual odds ratios.

All relevant data were stored in a MySQL database and the R statistical system (Venables and Smith, 2002) was used for the statistical analysis.

\section{Results}

\subsection{Preliminary results}

We graded the severity of a complication as high, medium or low if its average obstetrician-judged rank was 7 or more, 6 to 6.99, or less than 6, respectively. We then created 16 categories of complications by including complications observed on more than 120 occasions individually, and grouping the less frequently occurring complications within each severity group. Table 2 shows the prevalences of these 16 complication groups and the demographic risk factors.

No complication was recorded for 13,511 (70.1\%) of the 19,268 deliveries. The most common complications were cephalopelvic disproportion (1,244 cases, 6.5\%) and breech presentation (719, 3.7\%).

The most common places of residence of the mother were Bana and Sabarang subdistricts of Pattani City (15.4\% and $13.1 \%$, respectively), and the most common age groups were 25-29 (28.8\%) and 20-24 (26.6\%). With respect to gravidity, 43.4\% were second pregnancies. Most of the mothers were Islamic (58.4\%). In 34.8\% of cases education was either not stated or not one of the given categories on the form. Of the remainder, primary school was most common (28.6\%). Nearly half of the mothers (42.0\%) were housewives. The proportions of cases changed very little from year to year, ranging only from $10.3 \%$ in 2000 to $11.8 \%$ in 1997.

Table 3 shows the associations between each demographic risk factor and the binary high-risk outcome. Factors associated with high risk delivery complications were mothers aged 35 or more, having two or more previous pregnancies, Islamic religious affiliation, only primary school education and occupation farmer or gardener.

\subsection{Logistic regression}

Table 4 shows the same odds ratios for each risk factor as those in Table 3, together with corresponding 95\% confidence intervals, after adjusting for the other risk factors using logistic regression. With respect to the residence of the mother, the risks were found to be generally lower for mothers living in Pattani City with the exception of its central and eastern sub districts. Mothers aged 30 or more had higher risks than younger mothers, whereas those in delivering for the first time were also at higher risk than others. Women who had completed senior high school were at lower risk 
than others, whereas farmers and gardeners had higher risk of complications. There was no evidence of a trend over the period 1997-2005.

Adjusting for all the measured socioeconomic factors reduced the odds ratios for Islamic mothers compared to those of other religious affiliation from 1.6 to 1.4, respectively, but the relative risks remained highly statistically significant and substantially greater than 1 , with lower bound 1.26 for the $95 \%$ confidence interval.

\subsection{Association between outcomes}

In most maternal morbidity studies a one-minute Apgar score of 7 or less is regarded as an indication of risk signaling that special care is required (Chandra, 1997).

Table 5 shows odds ratios describing the associations between the risks based on the complication severity score and the conventional neonatal morbidity measures 1-minute Apgar score and birth weight group. It shows how the risks based on the Apgar-1 scores may be quantified into six groups with decreasing Apgar-1 score and higher complication-based risk; whereas those based on the very low, low and normal birth weight groups also neatly separate into three complication-based severity groups.

\section{Discussion}

The present study confirms the accepted wisdom Graham (1998) that the highest risks to newborns arise from specific pregnancy related complications: severe pregnancy-induced hypertension, eclampsia and thick mecomium stain. The study showed that rural residence, age, first pregnancy, Islamic mothers, lower educational completion and strenuous occupation are risk factors.

The higher risk among rural residence mothers may be due to the longer distance to access health care services or the difficulty of transportation from living place to the hospital. This result supports a European study finding that rural populations have higher maternal and perinatal mortality than corresponding urban populations (WHO, 2005).

Mothers aged 30 or more had higher risks than younger mothers. This confirms results reported by Uma (2006), Srisomboon (1994) and the Public Health, University of California (1994). Mothers delivering for the first time were at higher risk than others. This result agrees with a study conducted by Islam et al. (2004).

Women who had completed senior high school were at lower risk than others. A similar result was reported by Grjibovski (2002). More highly educated mothers may know how to better take care of themselves during pregnancy. This result is consistent with Raum et al. (2001).

Farmers and gardeners comprised only a small proportion of the study sample but had higher risk of complications. This could be due to their lower income or inferior nutrition.

Islamic mothers had higher risk than others, even after adjusting for all other recorded socio-demographic factors.

Since mothers who had had previous caesarean births were excluded from our study because a complication was not recorded for them even if one existed, it is possible that the omission of these women from our study could have given rise to a selection bias, which could account at least in part for our result. This question is being examined in a separate study.

The result from this study can be applied for screening of pregnant women who are at risk of complications in public health. Education on good practice during pregnancy to prevent complication from developing should be implemented, for institutional early detection and quality of management of antenatal care. We found risk that Muslim women have higher neonatal morbidity risks, particularly those associated with severe pregnancy-induced hypertension, eclampsia and thick mecomium stain. Future more women aged over 30 years, lower education, being gardener or farmer and having first gravidity had higher risk of having neonatal morbidity.

\section{Acknowledgements}

We would like express our gratitude to Prof.Don McNeil for his suggestions. Thanks are also due to Director of Pattani Hospital for allowing us to use the data. This study was partly funded by the graduate school, Prince of Songkla University. 


\section{References}

Berg ,C.J., Harper, M.A., Atkinson, S.M., Bell, E.A., Brown, H.L., Hage, M.L., Mitra, A.G., Moise, K.J. Jr. \& Callaghan, W.M. (2005). Preventability of Pregnancy- Related Deaths: Results of a State Wide Review. Obstetrics and Gynecology, 106, 1228-1233.

Chandra, S., Ramji, S. \& Thirupuram, S. (1997). Perinatal asphyxia: multivariate analysis of risk Factors in hospital Births. Indian Journal Pediatrics, 34, 206-212.

Dangal,G. (2007). High risk pregnancy. Internet Journal of Gynecology and Obstetrics, 7, [Online] Available: http://www.ispub.com/ostia/index.php?xmlFilePath=journals/ijgo/vol7n1/risk.xml (February 2, 2008)

Filippi, V., Ronsmans, C., Campbell, O.M., Graham, W.J., Mills, A., Borghi, J., Koblinsky, M. \& Osrin, D. (2006). Maternal health in poor countries: the broader context and a call for action. The Lancet, 368,1535-41.

Graham, W. (1998). Every Pregnancy Faces Risk. Planned Parenthood Challenges, 1, 13-14.

Grjibovski, A., Bygren, L.O. \& Svartbo, B. (2002). Sociodemographic determinants of poor infant outcome in North West Russia. Pediatric and Perinatal Epidemiology, 16, 255-262.

Islam, M.A., Chowdhury, R.I., Chakraborty, N., Bari, W. \& Akhter, H. (2004). Factors associated with Delivery complications in rural Bangladesh. The European journal of contraception and reproductive health care, 9, $203-213$.

Khan, K.S., Wojdyla, D., Say, L., Gulmezoglu, A.M. \& Van Look, P.F. (2006). WHO analysis of cause of maternal death: a systematic review. The Lancet, 367, 1066-1074.

Kleinbaum, D.G. \& Klein, M. (2002) Logistic regression: a self-learning text. (2nd ed.) New York: Springer-Verlag, (Chapter1).

Ministry of Public Health. (2004). Mother and Child Health Status 2001-2003. Bangkok: Ministry of Public Health.

Pattani Public Health Provincial Office. (2005). A report on mother and child health care. Pattani: Pattani Public Health Provincial Office.

Public Health, University of California. (1994). Factors influencing perinatal and infant Mortality. Acta Obstetricia et Gynecologica Scandinavica, 73, 14-26.

Raum, E., Arabin, B., Schlaud, M., Walter, U. \& Schwartz, F.W. (2001). The impact of maternal education on intrauterine growth: a comparison of former West and East Germany. International Journal of Epidemiology, 30 , 81-87.

Srisomboon, J. \& Tongsong, T.C. (1994). Pregnancy Outcome in elderly women aged 35 years or Older. The Royal Thai College Obstetrician and Gynecologists, 6 (2), 121-127.

Uma, M., Reddy, Chia-Wen. K.O. \& Marian, W. (2006). Maternal age the risk of stillbirth throughout pregnancy in the United States. American Journal of Obstetrics and Gynecology, 195, 764-770.

Venables, W.N. \& Smith, D.M. (2002). The r development core team, an introduction to r: revised and updated. Bristol: Network Theory Ltd.

Wen, S.W., Huang, L., Liston, R., Heaman, M., Baskett, T., Rusen, I.D., Joseph, K.S. \& Kramer, M.S. (2005). Severe maternal morbidity in Canada 1991-2001. Canadian Medical Association Journal, 173, 1-6.

World Health Organization. (1999). Child Health Research Project Special Report. Geneva, World Health Organization.

World Health Organization. (2005). Maternal and newborn health in the WHO European Region: The challenges and the way forward. Geneva, Fact sheet EURO/03/05 Copenhagen. Geneva, World Health Organization. 
Table 1. Complication frequencies and average severities recorded by 11 obstetricians

\begin{tabular}{|c|c|c|c|c|c|}
\hline Complication & Count & Score & Complication & Count & Score \\
\hline None & 13511 & 0 & Birth before admission & 16 & 6.00 \\
\hline Cephalopelvic disproportion & 1244 & 6.18 & Prolapsed cord & 15 & 8.82 \\
\hline Breech presentation & 719 & 5.90 & Anemia & 15 & 4.36 \\
\hline Post term labour & 443 & 6.72 & Gestational edema & 15 & 1.45 \\
\hline Pre-term labour & 370 & 7.36 & Herpes & 15 & 5.90 \\
\hline Prolong stage 1 & 367 & 5.09 & Oligahydramios & 15 & 7.36 \\
\hline Premature membrane rupture & 352 & 6.27 & Abruption placenta & 14 & 8.36 \\
\hline Prolong stage 2 & 319 & 7.00 & Asthma & 14 & 4.27 \\
\hline Severe PI hypertension & 232 & 7.36 & Anancephalus & 13 & 8.73 \\
\hline Mild PI hypertension & 218 & 5.45 & Hydrocephalus & 12 & 7.91 \\
\hline Placenta previa & 172 & 5.55 & Polyhydramios & 10 & 5.81 \\
\hline Fetal distress & 161 & 8.36 & Home birth with midwife & 10 & 4.00 \\
\hline Not stated & 133 & 3.50 & Myoma uteri & 9 & 4.36 \\
\hline Dead fetus in utero & 123 & 9.00 & Condyloma & 7 & 5.09 \\
\hline Low fetal movement & 119 & 6.36 & Epilepsy & 6 & 5.82 \\
\hline Membrane leak > 24 hrs & 55 & 6.91 & Shoulder dystosia & 5 & 8.27 \\
\hline Postpartum hemorrhage & 55 & 1.36 & Fetal anomaly & 4 & 8.00 \\
\hline Transverse lie & 54 & 5.27 & Uterine rupture & 4 & 8.91 \\
\hline Retain placenta & 49 & 0.36 & Acute diarrhea & 4 & 3.36 \\
\hline Gestational diabetes & 43 & 6.18 & UTI in pregnancy & 3 & 5.00 \\
\hline Thick mecomium stain & 41 & 8.09 & Chronic HT + Accrevate & 3 & 7.10 \\
\hline Eclampsia & 38 & 8.55 & Gastroenteritis & 3 & 3.18 \\
\hline Occiput presentation & 31 & 2.36 & Gestational hypertension & 2 & 4.63 \\
\hline Overt diabetes & 30 & 7.27 & Pyelonephritis & 1 & 5.64 \\
\hline Hyperthyroid in pregnancy & 29 & 4.81 & Pulmonary edema & 1 & 6.91 \\
\hline Thalasemia in pregnancy & 26 & 6.10 & Trauma & 1 & 5.91 \\
\hline Antepartum hemorrhage & 24 & 6.00 & Gestational proteinurea & 1 & 1.50 \\
\hline Heart disease & 20 & 6.27 & Amniotic embolism & 1 & 8.20 \\
\hline Chronic hypertension & 20 & 6.36 & Malaria in pregnancy & 0 & 7.45 \\
\hline VDRL positive & 19 & 6.18 & Appendicitis & 0 & 5.09 \\
\hline Face presentation & 16 & 7.36 & Gut obstruction & 0 & 5.00 \\
\hline Fever & 16 & 5.36 & & & \\
\hline
\end{tabular}


Table 2. Distributions of complication outcome and demographic factors

\begin{tabular}{|c|c|c|c|}
\hline Variable & $\begin{array}{l}\text { Cases } \\
\text { Count }(\%)\end{array}$ & Variable & $\begin{array}{l}\text { Cases } \\
\text { Count }(\%)\end{array}$ \\
\hline Complication group: & & Age group: & \\
\hline None & $13511(70.1)$ & less than 20 & $1954(10.1)$ \\
\hline Prolong stage 1 & 367 ( 1.9$)$ & $20-24$ & $5120(26.6)$ \\
\hline Mild PI hypertension & $218(1.1)$ & $25-29$ & $5552(28.8)$ \\
\hline Placenta previa & $172(0.9)$ & $30-34$ & 4025 (20.9) \\
\hline Breech presentation & 719 ( 3.7$)$ & 35 or more & $2617(13.6)$ \\
\hline Other low severity & $483(2.5)$ & Gravid: 0 & $7232(37.5)$ \\
\hline Cephalopelvic disp. & $1244(6.5)$ & 1 & $8363(43.4)$ \\
\hline Prem membrane rupture & $352(1.8)$ & 2 or more & $3673(19.1)$ \\
\hline Post term labour & $443(2.3)$ & Islamic & $11255(58.4)$ \\
\hline Other medium severity & $343(1.8)$ & Other religion & 8013 (41.6) \\
\hline Prolong stage 2 & $319(1.7)$ & Education: & \\
\hline Pre term labour & 370 ( 1.9$)$ & Primary school & $5508(28.6)$ \\
\hline Severe PI hypertension & $232(1.2)$ & Junior high & $2674(13.9)$ \\
\hline Fetal distress & $161(0.8)$ & Senior high & $2013(10.4)$ \\
\hline Other high severity & $211(1.1)$ & Dipl/Bachelor & $2365(12.3)$ \\
\hline Dead fetus in utero & $123(0.6)$ & Other/not stated & $6708(34.8)$ \\
\hline Place of Residence: & & Occupation: & \\
\hline Anuru & $1176(6.1)$ & Housewife & $8085(42.0)$ \\
\hline Bana & $2976(15.4)$ & Govt officer & $741(3.8)$ \\
\hline Sabarang & $2533(13.1)$ & Farmer/gardener & $260(1.3)$ \\
\hline City-south & $1152(6.0)$ & Business & $1442(7.5)$ \\
\hline City-centre & $1292(6.7)$ & Worker & $3346(17.4)$ \\
\hline City-east & 939 ( 4.9) & Other/not stated & $5394(28.0)$ \\
\hline Narat/Yala/not stated & 724 ( 3.8$)$ & Year: 1997 & $2272(11.8)$ \\
\hline Nong Chik & $1475(7.7)$ & 1998 & $2105(10.9)$ \\
\hline KhokPho/Maelan & $1143(5.9)$ & 1999 & $2022(10.5)$ \\
\hline Pattani-east & 943 ( 4.9) & 2000 & $1978(10.3)$ \\
\hline Yaring & $1994(10.3)$ & 2001 & $2079(10.8)$ \\
\hline Rusamilae & 1315 ( 6.8) & 2002 & $2210(11.5)$ \\
\hline Yarang & $680(3.5)$ & 2003 & $2162(11.2)$ \\
\hline Pattani-south & $383(2.0)$ & 2004 & $2202(11.4)$ \\
\hline Songkla & $543(2.8)$ & 2005 & $2238(11.6)$ \\
\hline
\end{tabular}


Table 3. High risk complication prevalence and associations with demographic factors

\begin{tabular}{|c|c|c|c|}
\hline Risk factor & Count $(\mathrm{OR})((95 \% \mathrm{CI})$ & Risk factor & Count (OR) (95\% CI) \\
\hline Residence: & & Religion: & \\
\hline Anuru & $57(0.48)(0.36-0.66)$ & Islamic & 968 (1.59) (1.42-1.78) \\
\hline Bana & $165(0.56)(0.45-0.69)$ & Other religion $*$ & 448 \\
\hline Sabarang & $147(0.58)(0.47-0.73)$ & Education: & \\
\hline City-south & $83(0.74)(0.56-0.96)$ & Primary school* & 460 \\
\hline City-centre & $91(0.72)(0.73-1.25)$ & Junior high & $194(0.86)(0.72-1.02)$ \\
\hline City-east & $86(0.96)(0.73-1.25)$ & Senior high & $131(0.76)(0.62-0.93)$ \\
\hline Nar/Yala/NS & $43(0.60)(0.43-0.84)$ & Dipl/Bachelor & $114(0.56)(0.45-0.69)$ \\
\hline Nong Chik & $121(0.85)(0.67-1.08)$ & Other/not stated & $517(0.92)(0.80-1.04)$ \\
\hline KhokPho/Maelan & 85 (0.76) (0.58-1.00) & Occupation: & \\
\hline Pattani-east & $71(0.77)(0.58-1.03)$ & Housewife * & 600 \\
\hline Yaring * & 190 & Govt officer & $34(0.60)(0.42-0.85)$ \\
\hline Rusamilae & $107(0.84)(0.66-1.08)$ & Farmer/gardener & $36(2.00)(1.40-2.88)$ \\
\hline Yarang & 76 (1.19) (0.90-1.58) & Business & $127(1.20)(0.99-1.47)$ \\
\hline Pattani-south & $42(1.17)(0.56-0.96)$ & Worker & $234(0.94)(0.80-1.10)$ \\
\hline Songkla & $52(1.01)(0.73-1.39)$ & Other/not stated & $385(0.96)(0.84-1.10)$ \\
\hline Age group: & & Budget year: & \\
\hline less than 20 & $145(1.07)(0.88-1.31)$ & 1997 & $171(1.02)(0.81-1.28)$ \\
\hline $20-24 *$ & 357 & 1998 & $144(0.92)(0.73-1.16)$ \\
\hline $25-29$ & $347(0.89)(0.76-1.04)$ & 1999 & 173 (1.17) (0.93-1.47) \\
\hline $30-34$ & $297(1.06)(0.91-1.25)$ & 2000 & $146(1.00)(0.79-1.26)$ \\
\hline 35 or more & $270(1.53)(1.30-1.81)$ & $2001 *$ & 154 \\
\hline Gravidity: & & 2002 & $173(1.06)(0.85-1.33)$ \\
\hline $0 *$ & 596 & 2003 & $156(0.97)(0.77-1.23)$ \\
\hline 1 & 475 (0.67) (0.59-0.76) & 2004 & $131(0.79)(0.62-1.01)$ \\
\hline 2 or more & $345(1.15)(1.00-1.33)$ & 2005 & $168(1.01)(0.81-1.27)$ \\
\hline
\end{tabular}

* Referent group for odds ratio (OR) calculation 
Table 4. Adjusted odds ratios for high risk complications

\begin{tabular}{|c|c|c|c|}
\hline Risk factor & $\begin{array}{c}\text { cases } \\
\text { OR }(95 \% \mathrm{CI})\end{array}$ & Risk factor & $\begin{array}{c}\text { cases } \\
\text { OR }(95 \% \mathrm{CI})\end{array}$ \\
\hline Residence: & & Religion: & \\
\hline Anuru & $0.59(0.44-0.81)$ & Islamic & $1.44(1.26-1.64)$ \\
\hline Bana & $0.66(0.52-0.82)$ & Other relig * & 1 \\
\hline Sabarang & $0.69(0.55-0.87)$ & Education: & \\
\hline City-south & $0.73(0.55-0.95)$ & Primary $*$ & 1 \\
\hline City-centre & $0.79(0.61-1.03)$ & Junior high & $0.90(0.75-1.08)$ \\
\hline City-east & $0.93(0.71-1.22)$ & Senior high & $0.75(0.61-0.92)$ \\
\hline Nar/Yala/NS & $0.73(0.52-1.04)$ & Dipl/Bach & $0.54(0.43-0.69)$ \\
\hline Nong Chik & $0.94(0.73-1.19)$ & Other/NS & $1.16(0.95-1.43)$ \\
\hline KP/Maelan & $0.93(0.71-1.23)$ & Occupation: & \\
\hline Pattani-east & $0.94(0.70-1.25)$ & Housewife * & 1 \\
\hline Yaring * & 1 & Govt officer & $0.77(0.52-1.14)$ \\
\hline Rusamilae & $1.05(0.81-1.35)$ & Farmer/G & $1.63(1.12-2.38)$ \\
\hline Yarang & $1.16(0.87-1.54)$ & Business & $1.19(0.97-1.46)$ \\
\hline Pattani-south & $1.17(0.82-1.68)$ & Worker & $1.01(0.86-1.19)$ \\
\hline Songkla & $1.19(0.85-1.65)$ & Other/NS & $0.58(0.41-0.82)$ \\
\hline Age group: & & Budget year: & \\
\hline less than 20 & $0.93(0.75-1.14)$ & 1997 & $1.37(0.93-2.01)$ \\
\hline $20-24 *$ & 1 & 1998 & $1.26(0.85-1.86)$ \\
\hline $25-29$ & $1.01(0.86-1.18)$ & 1999 & $1.33(1.03-1.73)$ \\
\hline $30-34$ & $1.22(1.02-1.46)$ & 2000 & $1.01(0.80-1.29)$ \\
\hline 35 or more & $1.58(1.29-1.93)$ & $2001 *$ & 1 \\
\hline Gravidity: & & 2002 & $1.06(0.85-1.33)$ \\
\hline $0 *$ & 1 & 2003 & $0.96(0.76-1.22)$ \\
\hline 1 & $0.59(0.51-0.67)$ & 2004 & $0.79(0.62-1.01)$ \\
\hline 2 or more & $0.72(0.60-0.86)$ & 2005 & $1.01(0.80-1.27)$ \\
\hline
\end{tabular}

Table 5. Associations between conventional neonatal morbidity outcomes and complication based risk outcome

\begin{tabular}{ccccc}
\hline & $\begin{array}{c}\text { conventional } \\
\text { neonatal } \\
\text { morbidity }\end{array}$ & \multicolumn{2}{c}{ Number of case } & OR (95\% CI) \\
High risk & Low risk & \\
\hline Apgar -1 score & $9-10^{*}$ & 856 & 16579 & 1 \\
& 8 & 132 & 708 & $3.6(3.0-4.4)$ \\
& 7 & 66 & 206 & $6.2(4.7-8.2)$ \\
& 6 & 52 & 115 & $8.8(6.3-12.2)$ \\
& $1-5$ & 133 & 171 & $15.1(11.9-19.1)$ \\
Birth Weight & $2500^{*}$ & 1013 & 16632 & $47.0(35.4-62.2)$ \\
\hline $2000-2499$ & 195 & 1043 & $3.1(2.6-3.6)$ \\
& $<2000$ & 208 & 177 & $19.3(15.6-23.8)$ \\
\hline
\end{tabular}

